\title{
John T. Dunlop e os 50 Anos do Industrial Relations Systems*
}

\author{
Carlos Henrique Horn \\ Fernando Coutinho Cotanda \\ Walter Arno Pichler
}

\section{INTRODUÇÃO}

\begin{abstract}
tradição anglo-americana de estudo das relações de trabalho (inA dustrial relations) nunca chegou a marcar forte presença na academia brasileira. Há escassa produção científica nacional que utiliza a literatura dessa tradição de pesquisa como sua fonte de referência, assim como, diferentemente do que se passou nos países de língua inglesa, nunca se constituíram, no Brasil, programas de graduação ou de pós-graduação stricto sensu específicos sobre relações de trabalho. A investigação científica e a formação profissional correspondentes aos assuntos do mundo do trabalho permanecem amarradas às disciplinas consolidadas na área - administração, direito, economia, história, sociologia, psicologia. Portanto, não chega a causar espanto que uma
\end{abstract}

\footnotetext{
* A maior parte deste artigo foi originalmente apresentada na II Conferência Brasileira de Relações de Emprego e Trabalho, organizada pelo Instituto Brasileiro de Relações de Emprego e Trabalho (Ibret), na Universidade de São Paulo (USP), em 17 e 18 de novembro de 2008. Os autores registram a importância, para sua elaboração, das discussões sobre a obra de Dunlop ocorridas no Grupo de Estudos de Relações de Trabalho, em 2008, e que também contaram com a presença de Cássio da Silva Calvete (Departamento Intersindical de Estatística e Estudos Socioeconômicos - Dieese), Marilis Lemos de Almeida (Universidade Federal do Rio Grande do Sul - UFRGS) e Raul Luís Assumpção Bastos (Fundação de Economia e Estatística Siegfried Emanuel Heuser - FEE). Agradecemos ainda os comentários de dois pareceristas anônimos da revista $D A D O S$, que ajudaram a melhorar o resultado final. Eximimos de qualquer responsabilidade a todos, colegas do Grupo de Estudos e pareceristas, pelos pontos de vista expressos no texto.
}

DADOS - Revista de Ciências Sociais, Rio de Janeiro, Vol. 52, nํ4, 2009, pp. 1047 a 1070. 
obra tão marcante na tradição anglo-americana, como Industrial Relations Systems (IRS), de John Thomas Dunlop, publicada em 1958, pouco tenha influenciado os estudos sobre o trabalho ${ }^{1}$ e nem sequer tenha merecido, até onde alcança nosso conhecimento, uma tradução para o português em nosso país ${ }^{2}$.

Há um consenso, na literatura especializada, sobre a enorme influência exercida pelo IRS na tradição de estudos do industrial relations (IR), sendo essa obra considerada a primeira tentativa sistemática de elaboração de um arcabouço teórico no campo das relações de trabalho (Müller-Jentsch, 2004). Ainda que haja divergências sobre os resultados da empreitada do autor, ou seja, do quão bem-sucedido teria sido Dunlop em sua busca de uma teoria geral das relações de trabalho, não resta dúvida quanto às consequências do IRS na determinação de uma agenda de pesquisa e na formulação científica do campo na segunda metade do século XX. Kaufman (2004), não exatamente um autor simpático ao IRS, afirma em sua magistral história do industrial relations: "[...] o livro é largamente visto como uma das mais influentes peças acadêmicas já escritas no campo e vários a considerariam o trabalho seminal de teoria das relações de trabalho" (ibidem:250; tradução dos autores).

Este artigo apresenta uma resenha do IRS sem, contudo, exaurir as questões levantadas por sua publicação e que deram origem a uma farta literatura. Acreditamos que o texto se justifique exatamente pelo desconhecimento relativamente generalizado no Brasil de uma obra tão importante. Pretende-se, com isso, ajudar a diminuir uma lacuna no momento de seus recém-completados 50 anos da edição original.

Além desta introdução, o artigo possui cinco seções. Na primeira, apresentamos uma nota biográfica sobre o autor. Na segunda, delineamos o contexto acadêmico de surgimento do Industrial Relations Systems, associando-o à chamada era dourada do IR norte-americano e, em particular, a um amplo projeto de pesquisa denominado Estudo Interuniversitário dos Problemas do Trabalho no Desenvolvimento Econômico. A terceira seção destina-se à exposição de conteúdos básicos do IRS. Nela, delimitamos os objetivos de Dunlop em sua obra e discorremos sobre o conceito e a estrutura de um sistema de relações de trabalho. Na seção seguinte, enfrentamos, ainda que de modo meramente exploratório, a questão das razões da ausência da obra de Dunlop dos estudos sobre relações de trabalho no Brasil. Por fim, na 
quinta seção, discutimos algumas lições do IRS que julgamos relevantes e que permanecem válidas para o estudo das relações de trabalho.

\section{NOTA BIOGRÁFICA SOBRE 0 AUTOR}

John Thomas Dunlop nasceu em Placerville, no Estado da Califórnia, em 5 de julho de 1914. Filho de missionários presbiterianos, passou parte da infância nas Filipinas. Dunlop concluiu seu curso de graduação em economia na Universidade da Califórnia, Berkeley, em 1935, onde também obteve seu doutoramento quatro anos mais tarde. Em 1938, ingressou na Universidade de Harvard para lecionar economia, concentrando seu interesse nos estudos do trabalho, mas não se limitando aos assuntos dessa área, o que se prolongou até o ano de sua aposentadoria, em 1985. Um traço básico de sua atuação profissional, não obstante, foi a proximidade que sempre manteve com as relações sociais reais que constituíram o objeto de sua investigação. Vale dizer que Dunlop foi um economista de múltiplas atividades, tendo combinado sua base acadêmica em Harvard com incessantes participações no serviço público e na mediação de conflitos do trabalho no setor privado.

No setor público, entre 1943 e 1945, ainda quando jovem economista, Dunlop ocupou a direção de pesquisa no National War Labor Board, órgão com atribuições associadas à manutenção da paz industrial, ao controle dos salários e ao aumento da produtividade no período da guerra. Posteriormente, participou de inúmeros comitês em todos os governos norte-americanos, até o do presidente Clinton, quando coordenou a White House Commission on Future of Worker/Management Relations, que ficou conhecida como Comissão Dunlop. O ponto alto de sua participação no serviço público ocorreu no governo Ford, quando exerceu o cargo de secretário do Trabalho, tendo se notabilizado pela renúncia motivada por uma questão de princípio. Dunlop teria se comprometido com um projeto de lei que ampliava os direitos de realização de piquetes aos sindicatos da construção civil em contrapartida à moderação nas demandas salariais desses sindicatos, mas o projeto veio a ser vetado pelo presidente, o que teria sido entendido como uma desautorização da negociação conduzida por seu secretário.

John Dunlop foi um dos mais proeminentes membros de uma geração de economistas do trabalho que gravou sua marca na tradição do industrial relations e da qual fizeram parte, entre outros, Clark Kerr, Richard Lester, Arthur Ross, Charles Myers, Neil Chamberlain, Albert 
Rees e Frederick Harbison. Apesar da formação convencional recebida pela maioria desses economistas, sua perspectiva analítica os afastou do mainstream da profissão, dominado pelo enfoque neoclássico expresso nos manuais de teoria dos preços, constituindo, ainda que não formalmente, uma corrente denominada economistas institucionalistas do trabalho (Kaufman, 1993). Foi dessa corrente de economistas que partiu o impulso principal para a fundação da Industrial Relations Research Association (Irra) ${ }^{3}$, em 1947, associação criada com o intuito de promover debates e de divulgar a pesquisa de acadêmicos e de profissionais das relações de trabalho nos Estados Unidos. Dunlop presidiu a Irra em 1960.

Foi também autor de inúmeros artigos e livros, dos quais se destacam: Wage Determination under Trade Unions (1944); Industrial Relations Systems (1958); Industrialism and Industrial Man (com Clark Kerr, Frederick Harbison e Charles Myers, 1960); e Dispute Resolution, Negotiation and Consensus Building (1984). John Dunlop faleceu em Boston, no Estado de Massachusetts, em 2 de outubro de 2003.

\section{CONTEXTO ACADÊMICO DA OBRA}

Industrial Relations Systems foi publicado no ápice de um período considerado a era dourada do IR nos Estados Unidos, o qual, cronologicamente, cobre o decênio entre os finais das décadas de 1940 e 1950. Entre outros traços salientes, essa época se caracterizou por uma vasta produção científica sobre assuntos atinentes às relações de trabalho envolvendo pesquisadores de diferentes disciplinas e matizes teóricos. Conforme aponta Kaufman, "como um resultado desse extenso envolvimento multidisciplinar, a pesquisa em relações de trabalho ganhou fôlego até então desconhecido em seus temas, perspectivas teóricas e métodos de pesquisa" (1993:92; tradução dos autores).

Um dos empreendimentos mais relevantes da pesquisa sobre relações de trabalho no período, e que se estendeu por mais de duas décadas, foi o Estudo Interuniversitário dos Problemas do Trabalho no Desenvolvimento Econômico, um ambicioso projeto coordenado por Clark Kerr (Universidade da Califórnia, Berkeley), John Dunlop (Universidade de Harvard), Frederick Harbison (originalmente da Universidade de Chicago; posteriormente, da Universidade de Princeton) e Charles Myers (MIT). Iniciado no ano de 1954, com algum trabalho preliminar em anos anteriores, o Estudo Interuniversitário fez parte do boom de análises comparativas das relações de trabalho entre países que se ve- 
rificou nos anos 1950. Esse projeto específico atingiu, contudo, uma escala sem precedentes, tendo envolvido 78 pesquisadores e coletado, em seu primeiro quinquênio de atividade, informações referentes a 35 países. Estes formaram um conjunto intencionalmente heterogêneo, cobrindo economias de mercado desenvolvidas (Alemanha, Japão, Estados Unidos, por exemplo), economias de planejamento central (União Soviética) e economias em processo de industrialização recente (Índia, Egito, Indonésia, Brasil).

O Estudo Interuniversitário deu origem a dezenas de publicações, entre as quais se encontra o Industrial Relations Systems ${ }^{4}$. Não obstante, o texto que provavelmente constitui sua marca registrada é Industrialism and Industrial Man, publicado em 1960, em uma coautoria dos quatro coordenadores do projeto. O livro representa uma síntese das principais conclusões a que chegaram os autores naquele momento do Estudo e, de acordo com Kaufman, "representa a maior e mais extensa tentativa de teorização no campo das relações de trabalho nos Estados Unidos e, justificadamente, na história global desse campo de estudos" (2004:256; tradução dos autores). Nele, os autores partem da questão orientadora geral do Estudo Universitário, a dos impactos da industrialização sobre a vida em sociedade ${ }^{5}$, e, em particular, sobre as relações de trabalho; abordam as diferentes trajetórias nacionais de industrialização associadas a diferentes tipos de elite industrializante; e formulam sua predição sobre o futuro como uma resultante do confronto entre fontes que conduzem à diversidade e fontes que pressionam por uniformidade, sugerindo que a tendência básica dos países é a de evoluírem para uma configuração que denominam industrialismo pluralista ${ }^{6}$. Tal predição veio a ser posteriormente referida, na literatura do industrial relations, como a tese da convergência ao modo anglo-americano de relações de trabalho, tendo suscitado controvérsias que se estendem aos dias de hoje. Uma das principais conclusões do Industrialism and Industrial Man, notadamente a que se refere ao desenvolvimento de sistemas nacionais de relações de trabalho e ao papel das elites industrializantes, já havia sido antecipada por Dunlop no capítulo 7 do IRS.

\section{INDUSTRIAL RELATIONS SYSTEMS}

\section{Objetivo e Composição da Obra}

O objetivo fundamental de Dunlop, no Industrial Relations Systems, é esclarecido já nas páginas iniciais do prefácio. Trata-se de apresentar 
"uma teoria geral de relações de trabalho; ele [o livro] busca oferecer ferramentas de análise para interpretar e entender o mais amplo leque de fatos e de práticas nas relações de trabalho" (Dunlop, 1993:x; ênfase e tradução dos autores). As relações que são o objeto focal da teoria configuram um complexo de interações de administradores de empresas, trabalhadores e agências governamentais que caracterizam as sociedades que atravessaram processos de industrialização. Em suma, essas relações compreendem a relação de emprego assalariado enquanto seu núcleo e o conjunto de relações entre pessoas e instituições que se forma em torno da relação básica de emprego.

Ainda ao expor o objetivo do IRS, Dunlop acrescenta alguns esclarecimentos que revelam motivações e apontam aspectos capitais de sua construção teórica. Assim, o autor acreditava que a teoria pudesse ser útil para interpretar a experiência das relações de trabalho: (i) em empresas e em setores de atividade econômica, bem como para comparações entre eles; (ii) em países e para comparações internacionais; (iii) ao longo do tempo, no curso do desenvolvimento econômico. Ao fazê-lo, deveria ter como tarefa central explicar por que determinadas normas que governam a relação de emprego e as demais relações no mundo do trabalho são estabelecidas em certos sistemas de relações de trabalho, e como e por que as normas mudam em face de pressões exercidas sobre o sistema (ibidem:xi) ${ }^{7}$.

O conceito de sistema de relações de trabalho, a par de dar causa ao título da obra ${ }^{8}$, ocupa o centro das atenções do autor ao longo do livro. Industrial Relations Systems é composto de nove capítulos ${ }^{9}$. Os quatro primeiros destinam-se a esclarecer o que é um sistema de relações de trabalho e qual é sua estrutura, com atenção principal às relações de conformidade entre os contextos e as normas do sistema. Os capítulos 5 e 6 fornecem uma ilustração do poder analítico do conceito de sistema quando aplicado a relações de trabalho com normas determinadas no âmbito setorial. Os setores de atividade que servem de exemplo são os da extração de carvão e a construção civil. Nos capítulos 7 e 8, o autor utiliza o conceito de sistema para tratar das relações de trabalho no plano de uma nação e com base em um recorte longitudinal, visto que sua preocupação é quanto aos fatores que incidem no desenvolvimento de sistemas nacionais de relações de trabalho e ao modo como o desenvolvimento econômico afeta a regulação da relação de emprego. O livro termina com uma síntese, no capítulo 9, sob o título de "Teoria Geral das Relações de Trabalho". Em vista de sua absoluta relevância, deta- 
lhamos, na próxima subseção, o conceito de sistema de relações de trabalho.

\section{Sistema de Relações de Trabalho: Conceito e Estrutura}

As relações de trabalho em um país ou em uma comunidade de trabalho são percebidas por Dunlop como um sistema, isto é, como um todo compreensivo de elementos inter-relacionados. Esse sistema é composto de atores, contextos, ideologia e normas. Os atores interagem sob a influência de determinados contextos - que incluem a tecnologia, os mercados e a distribuição do poder na sociedade em geral-, e essa relação envolve, igualmente, uma ideologia que, de acordo com o autor, contribui para definir seus papéis, bem como para integrar o sistema. O produto de um sistema de relações de trabalho constitui uma rede de normas que governa a relação de emprego e as demais relações entre os agentes do mundo do trabalho ${ }^{10}$. Mudanças no ambiente, no relacionamento entre os atores ou nos entendimentos compartilhados por eles podem afetar as normas do sistema ou até mesmo o próprio sistema.

Os atores de um sistema de relações de trabalho compreendem três tipos de hierarquia ou organização: trabalhadores, administradores e agências governamentais ou privadas especializadas.

A hierarquia de trabalhadores é composta de organizações complementares ou rivais, formalmente estabelecidas, tais como sindicatos, associações, clubes, conselhos e organizações políticas, e formas pouco ou "não organizadas" em que os trabalhadores podem tratar coletivamente de seus interesses. Dunlop (1993:14 e 47) recorda que, em qualquer empreendimento produtivo permanente, os trabalhadores nunca estão inteiramente desorganizados. Quando um grupo de empregados trabalha junto por um determinado tempo, algum tipo de organização informal tende a surgir entre eles. Entre as formas "pouco organizadas" ou "não organizadas", o autor menciona, a título de ilustração, os círculos de qualidade, as comissões de prevenção de acidentes, os programas de participação de empregados, os grupos comunitários e os grupos formados espontaneamente para lidar com problemas específicos ou para reagir contra certos desenvolvimentos no local de trabalho (ibidem:14-15).

A hierarquia de administradores, por sua vez, não corresponde necessariamente ao proprietário dos ativos de capital. Os administradores podem ser públicos ou privados, ou uma combinação de ambos, ou seja, 
essa hierarquia inclui um leque variado de instituições. De acordo com o autor, em um dos extremos estão os empregadores privados individuais e as estruturas empresariais familiares; no outro, as grandes empresas multinacionais e as agências internacionais (ibidem:14). A exemplo do que ocorre com a hierarquia de trabalhadores, a definição sobre qual hierarquia específica de administradores é relevante para o processo de formulação das normas depende, entre outros fatores, do nível ou escopo do sistema de relações de trabalho - se empresa, setor, nação ou algum outro, como nos referiremos em seguida. Assim, a hierarquia que importa pode ser, entre outras, uma empresa privada, corporação pública ou associação (ou sindicato) patronal. Essencialmente, os atores relevantes dentro desse grupo são aquelas associações ou agrupamentos de empresas com poder (ou autoridade explícita, ou de fato) para participar do processo de tomada de decisões.

Finalmente, as agências especializadas incluem os organismos governamentais que desempenham um papel no sistema de relações de trabalho, aos quais Dunlop confere maior atenção, bem como as agências especializadas criadas pelos outros dois atores. O autor afirma que, em algumas sociedades, essas agências podem ter um papel tão amplo e decisivo que chega a anular o poder das hierarquias de administradores e de trabalhadores em todas as questões. Já em outras, seu papel pode ser tão limitado que permite uma ampla liberdade de ação das outras hierarquias (ibidem:48). Essas organizações podem exercer as mais diversas funções, tais como resolução de disputas, treinamento, estabelecimento de salários, cuidados de saúde, provimento de pensões e de aposentadorias, entre outras.

A interação dos atores ocorre sob a influência de três contextos relevantes, a saber: tecnologia, mercados e distribuição do poder na sociedade em geral. Essas condições ambientais são, de acordo com o autor, decisivas na moldagem das normas estabelecidas em um sistema de relações de trabalho (ibidem).

O contexto tecnológico diz respeito às características do local de trabalho e às operações e às funções de trabalho. Segundo Dunlop, os locais de trabalho podem variar no tocante a vários aspectos: mobilidade, relação com a residência dos trabalhadores, duração do trabalho e tamanho da força de trabalho. Já o tipo de operação de trabalho diz respeito ao conteúdo, ao ritmo e à jornada de trabalho. Dunlop (1993:48-49) sustenta que os fatores tecnológicos afetam a forma de organização de ad- 
ministradores e empregados, os problemas colocados para as administrações e as características requeridas pela força de trabalho. Os fatores tecnológicos colocam diferentes problemas para administradores e empregados e, ao mesmo tempo, limitam o rol de soluções factíveis para esses problemas, resultando em que diferentes ambientes tecnológicos determinam o aparecimento de normas distintas.

O contexto dos mercados compreende o mercado de produto, as limitações orçamentárias com que se defrontam as empresas e o mercado de trabalho. O mercado de produto pode variar conforme o caráter da concorrência (concorrência pura, oligopólio, monopólio) e o tipo de mercado (local, nacional, internacional; protegido ou exposto à concorrência). Já no caso de organizações produtivas cujos meios financeiros dependem, no todo ou em parte relevante, de transferências de recursos tributários, sua capacidade de financiamento está vinculada menos (ou não está vinculada) a seu desempenho de mercado do que a suas limitações orçamentárias. Esse tipo de contexto inclui, por fim, as características da força de trabalho, tais como étnicas, culturais, religiosas, nível de instrução e qualificação. O contexto dos mercados incide decisivamente no grau de liberdade no estabelecimento das normas, sendo particularmente relevante para questões como as de remuneração da força de trabalho, do timing de revisão das normas, da duração das normas e do treinamento da mão de obra.

Finalmente, o contexto do poder refere-se à distribuição do poder dos atores na sociedade. Isso se reflete, de acordo com Dunlop (ibidem:50), em seu prestígio, posição e autoridade, afetando indiretamente a interação dos atores em um sistema ao contribuir para sua estruturação. $\mathrm{O}$ autor assinala que, de modo geral, a distribuição do poder é decisiva na definição do status dos atores, ou seja, suas funções e formas de interação, sendo particularmente importante na determinação da função das agências governamentais especializadas. As funções e as formas de interação prescritas podem ser impostas "de fora", pela sociedade (como é o caso da legislação em um sistema empresarial), ou ser criadas pelo próprio sistema de relações de trabalho e, então, ser sancionadas ou reconhecidas pela comunidade.

O terceiro elemento constitutivo de um sistema de relações de trabalho, a ideologia, refere-se ao conjunto de ideias e de crenças compartilhadas pelos atores. De acordo com Dunlop, a ideologia define o papel e o lugar de cada ator, bem como as ideias que cada ator tem a respeito 
de seu lugar e do lugar dos outros na sociedade. Ela tem a função de integrar o sistema de relações de trabalho. Além disso, um sistema, para ser estável, requer congruência ou compatibilidade, em algum grau, entre as visões ou ideologias de cada ator.

O último elemento do sistema de relações de trabalho, a teia de normas (web of rules), é o resultado da interação dos atores ou a variável dependente do modelo. As normas abrangem uma ampla variedade de meios de expressão. Podem aparecer como obrigações formalmente estabelecidas em regulamentos e políticas da hierarquia de administradores, em regras de qualquer organização de trabalhadores, na legislação do trabalho, em decretos ou em outros tipos de decisão governamental, em decisões de tribunais, em decisões de agências especializadas criadas pelas hierarquias de administradores ou de trabalhadores, ou em acordos estabelecidos mediante negociação coletiva. Incluem, ainda, os costumes e tradições da comunidade de trabalho (ibidem:53).

Além das várias formas de expressão das normas, o autor igualmente as distingue, conforme o objeto de sua regulação, entre normas substantivas e normas de procedimento. As primeiras incluem as normas que regulam as compensações (remuneração) em todas as suas formas, os deveres e as performances esperadas de trabalhadores e as normas que definem os direitos dos trabalhadores. As segundas incluem os procedimentos para o estabelecimento de normas e os procedimentos para decidir sua aplicação a situações particulares ${ }^{11}$.

A autoridade dos atores e os procedimentos para estabelecer normas são aspectos cruciais de um sistema de relações de trabalho. As normas de procedimento constituem um produto das políticas públicas, da história e das tradições de um país, sendo consideravelmente uniformes no espaço nacional e relativamente estáveis ao longo do tempo. Ainda de acordo com Dunlop, a relevância das normas de procedimento é tal que se poderia distinguir um sistema de outro por meio da identificação do modo pelo qual as relações de trabalho são reguladas em uma dada realidade (ibidem:51). Por exemplo, um sistema nacional no qual a legislação estatal tenha proeminência no marco normativo e a função insignificante seja cumprida pelas negociações coletivas entre empresas e sindicatos é fundamentalmente diferente de um sistema em que as negociações coletivas exercem um papel relevante, quer seja este principal, quer seja complementar, na regulação da relação de emprego. 
A definição do grau de importância ou da autoridade dos atores na regulação das relações de trabalho está diretamente relacionada com a distribuição de seu poder na sociedade, vale dizer, com aqueles aspectos que Dunlop julga decisivos para a definição do status dos atores; e a autoridade é associada ao uso legítimo do poder. Salamon (1998:70-71) esclarece que o conceito de poder é empregado em dois sentidos: no primeiro, consiste na capacidade de alguém controlar os outros, de dar ordens, de impor instruções ou regulamentos para outros; no segundo, na capacidade de influir na tomada de decisões de outros. Essa influência pode ser exercida mediante a capacidade de forçar mudanças nas decisões de outros ou na capacidade de gerar uma influência implícita que pode ser parte integral do ambiente que é levado em conta por outros no processo de tomada de decisões ${ }^{12}$.

O conceito de sistema de relações de trabalho pode ser útil para analisar o processo de regulação das relações de trabalho em diferentes níveis. Assim, o escopo de um sistema pode abranger uma sociedade nacional, quando estaríamos tratando de um sistema nacional de relações de trabalho; pode, igualmente, referir-se às relações de trabalho em um setor de atividade econômica ou em uma região; e, finalmente, o sistema pode abranger um grupo econômico ou uma única empresa ou estabelecimento. Como assinala o próprio autor, "o conceito de sistema é formulado para exprimir duas ideias: o escopo ou contorno de um sistema pode variar conforme o foco se direcione para uma nação, setores de uma economia ou unidades menores coerentes; e o sistema indica um forte sentido de interdependência interna" (Dunlop, 1993:12; tradução dos autores).

Uma hipótese de Dunlop é que, quanto menor o escopo do sistema, maior o contexto e, por conseguinte, maior o peso do ambiente externo sobre a ação dos atores. Assim, por exemplo, em sistemas de relações de trabalho no âmbito de empresa ou grupo empresarial, os fatores ambientais dos mercados e da legislação seriam decisivos na formulação das normas, ao passo que, quando o sistema de relações de trabalho se confunde com o espaço nacional, os mercados perdem relevância relativa como um elemento do contexto e a própria legislação passa à condição de variável dependente ${ }^{13}$.

\section{AUSÊNCIA DE DUNLOP DO BRASIL: COMENTÁRIO EXPLORATÓRIO14}

O contraste entre a enorme influência exercida pelo Industrial Relations Systems nos estudos sobre as relações de trabalho em geral - particular- 
mente nas comparações entre sistemas nacionais - e sua virtual ausência como referência explícita de pesquisa na academia brasileira merece um comentário, ainda que meramente exploratório, sobre as possíveis razões dessa ausência. A hipótese que sugerimos nesta seção é a de que a limitada recepção de Dunlop no Brasil decorre de uma combinação entre dois fatores. O primeiro deles diz respeito à existência, em nosso país, de uma base fática consideravelmente diferente daquela em que vicejou o IRS, assim como diferente do objeto primordial de estudos do IR norte-americano desde meados dos anos 1930 - a saber, a regulação conjunta da relação de emprego por meio de negociação coletiva entre sindicatos e empresas. O segundo fator é o florescimento, nas escolas de economia e de sociologia brasileiras, de estudos sobre o trabalho ancorados em tradições intelectuais opostas e/ou desinteressadas (e, em alguns casos, refratárias ao pensamento proveniente dos Estados Unidos) no método, no arcabouço conceitual e nas soluções normativas para lidar com as relações de trabalho segundo o IR.

Não obstante a referência explícita irregular ao arcabouço dunlopiano na pesquisa brasileira e a falta de uma edição nacional do IRS - o que imediatamente contrasta com a expressiva presença editorial que a obra obteve em outros países, inclusive nos de língua espanhola -, a expressão "sistemas de relações de trabalho" foi amplamente acolhida no Brasil em período mais recente e hoje é de uso corrente em diferentes loci acadêmicos, profissionais e de representação de interesses que envolvem as relações de trabalho. Galvão (2002:8-11), em sua nota bastante crítica ao conceito de Dunlop, bem assinala que a expressão veio a se incorporar na literatura brasileira de fins dos anos 1990 por meio da economia do trabalho e do direito, com extensões a outras áreas da academia e da prática sindical. No entanto, a ampla acolhida da expressão "sistema de relações de trabalho", tributária da obra de Dunlop, não se traduziu necessariamente na recepção do enquadramento teórico por ele desenhado. O uso da terminologia sistêmica inscreve-se, majoritariamente, em uma perspectiva polissêmica que, no mais das vezes, não traduz a complexidade dos significados empregados pelo autor; apenas remete à existência de relações de interdependência e de interpenetração das variáveis que concorrem para a explicação dos fenômenos ligados à relação de emprego.

A abordagem do IR para as relações de trabalho, dentro da qual se deve situar o texto de Dunlop, tem suas origens mais próximas nas obras de Sidney e Beatrice Webb, na Grã-Bretanha, e de John Rogers Commons, 
nos Estados Unidos. Kaufman (2004), em sua mencionada história sobre esse campo de estudos, não apenas situa nos Estados Unidos o espaço de nascimento do IR, em um processo que se desdobrou em múltiplas iniciativas acadêmicas e profissionais durante os anos 1920, como também demonstra que, pelo menos até a década de 1960, a difusão dessa tradição de pesquisa e de administração dos conflitos do trabalho se circunscreveu, basicamente, a um espaço anglo-americano (Estados Unidos, Reino Unido, Canadá, Nova Zelândia e Austrália). Com a criação da Associação Internacional de Relações de Trabalho (International Industrial Relations Association) em 1966, o campo de estudos viria a expandir consideravelmente suas fronteiras, encontrando adeptos em todos os continentes.

Se tomarmos, portanto, os anos 1960 como um momento em que seria provável o ingresso da tradição do IR, em particular do IRS, no Brasil, é razoável supor que a obra de Dunlop não tenha merecido a devida atenção antes de tudo porque lhe poderia ser atribuída certa incapacidade de lidar com o caso brasileiro. Nesse período, as bases do sistema brasileiro de relações de trabalho encontravam-se assentadas e correspondiam ao regime instituído nos anos 1930, notadamente um sistema marcado pelo forte intervencionismo estatal na regulação das relações trabalhistas em geral e na organização e na ação dos atores sociais. As entidades sindicais patronais e, sobretudo, de trabalhadores careciam de liberdade para exercer plenamente sua função de representação de interesses e, portanto, para negociar os termos da relação de emprego $^{15}$. Esse modelo contrastava fortemente com o modelo norte-americano pós-New Deal, caracterizado na literatura como um sistema de regulação baseado na negociação coletiva (collective bargaining-based industrial relations).

Assim, quem quer que tenha recebido uma notícia sobre o IRS na década de 1960, pode muito bem ter descartado sua utilidade para o estudo do caso brasileiro sob a premissa de que a obra aborda exclusivamente os sistemas em que a regulação conjunta e a hierarquia dos trabalhadores detenham alguma importância para a definição das normas - o que se põe em visível contraste com um sistema em que a função de regulação das relações de trabalho se exerce pelo Estado por meio da lei, de uma Justiça especializada e do controle sobre as organizações patronais e de trabalhadores, fazendo com que as demandas dos empregados e os conflitos trabalhistas em geral fossem encaminhados ao escrutínio de magistrados em vez de solucionados pelas partes por meio de 
processos negociais. Tal leitura sobre o objeto do IRS, ainda que em nosso entender se equivoque ao limitar sua abrangência a processos formalizados de negociação coletiva, estava ademais em conformidade com o fato de a academia norte-americana concentrar seus estudos sobre as relações de trabalho justamente em temas sobre sindicatos e negociações coletivas.

A identificação do IRS como sendo uma obra sobre sistemas de negociação coletiva, por mais que nos pareça equivocada, encontrou guarida em um sem-número de pesquisadores das relações de trabalho. Kaufman, por exemplo, escreve:

[...] embora, em princípio, a noção de um sistema de relações de trabalho seja genérica e cubra todas as formas de relações de emprego, na exposição de Dunlop a ideia é grandemente contígua das formas coletivas e organizadas de relações de trabalho (por exemplo, sistemas de relações entre gerentes e o trabalho organizado) (2004:254; tradução dos autores).

No Brasil, uma expressão dessa identidade está na afirmação de Melo e Carvalho Neto (1998:39) de que "o modelo dunlopiano baseia-se no instituto da negociação coletiva". Portanto, uma primeira explicação para o longo silêncio sobre o IRS no Brasil está na virtual ausência, a té o final dos anos 1970, de regulação das relações de trabalho conjuntamente por empresas e sindicatos mediante negociação coletiva.

Esse primeiro fator explicativo remete, ademais, à cultura política brasileira no que se refere ao modo de encarar o conflito trabalhista. No Brasil, atores relevantes da cena trabalhista apresentam um longo histórico de dificuldades para conviver com a pluralidade de interesses e o conflito inerente à relação de emprego. Desde há muito que o conflito é valorado negativamente, algo que deve ser eliminado, expurgado, absorvido pelo Estado. A necessidade da permanente ação do Estado sobre as relações de trabalho projeta-se como o fio condutor da prática política hegemônica no Brasil. Na versão getulista, essa necessidade foi sistematicamente reiterada, como ilustra o seguinte excerto:

A organização do trabalho, no sentido que se lhe deve dar, num momento conturbado e de profundas transformações sociais e econômicas como a atual, não pode realizar-se com proveito para as classes patronais e benefícios para os operários, senão mediante inteligente, ponde- 
rada e sistemática coordenação para conciliar e garantir os seus mútuos interesses [...] (Getulio Vargas apud Humphrey, 1982:19).

O esquema dunlopiano parte da premissa da legitimidade da organização e da ação dos atores na defesa de seus interesses, não cabendo ao Estado um papel de tutela absoluta. De modo consistente com essa visão, Dunlop e seus companheiros da corrente institucionalista do trabalho posicionaram-se do lado oposto ao dos economistas da Escola de Chicago, que professavam a necessidade de eliminar a interferência nociva dos sindicatos na regulação da relação de emprego. Para os institucionalistas, a sociedade deve reconhecer os sindicatos como representantes legítimos dos trabalhadores. Portanto, o IRS poderia ser entendido não apenas como texto destituído de poder explicativo do caso brasileiro (dimensão teórica), mas também em completo desacordo com a prática política predominante no país para a solução dos conflitos do trabalho (dimensão de solução de problemas).

A hipótese sobre a percepção de limitada utilidade do IRS em sua dimensão teórica reforça-se ao lembrarmos que, considerando os usos que Dunlop atribuía à sua obra - comparações entre setores de atividade e empresas em um dado sistema, comparações entre sistemas nacionais e relações de trabalho no curso do desenvolvimento -, são exatamente os estudos sobre comparações internacionais que mais vêm se utilizando do arcabouço dunlopiano. Tais comparações, salvo muito recentemente, não atraíram a atenção da academia brasileira.

O Industrial Relations Systems não teria recebido guarida na pesquisa brasileira não apenas em decorrência de sua suposta pouca utilidade para entender o país ou para prover soluções aos conflitos do trabalho diante do legado autoritário brasileiro, mas também porque importantes tradições teórico-metodológicas de estudos do trabalho na economia e na sociologia, em larga medida dominantes no Brasil dos anos 1960, não abrigavam os enfoques anglo-americanos do IR. No caso da economia, as duas principais vertentes de ensino e pesquisa sobre o mercado de trabalho bebiam em fonte concorrente da abordagem sistêmica do IR: a economia neoclássica, ou aparentemente desinteressada, e o estruturalismo-marxismo da Comissão Econômica para a América Latina e o Caribe (Cepal). Quanto à primeira, basta referir que um dos principais fundamentos na criação do campo de estudos das relações de trabalho nos Estados Unidos esteve justamente na oposição - teórica e normativa -, considerando o trabalho, como fazem os modelos 
neoclássicos básicos, uma mercadoria similar a qualquer outra. Já em relação à tradição cepalina, não deixa de ser intrigante, dada sua contiguidade, por que a literatura da economia institucionalista do trabalho norte-americana do tipo IR não tenha recebido atenção igual à que receberam os teóricos dos mercados segmentados de trabalho.

No campo da sociologia brasileira, cujos estudos sobre o trabalho se haviam iniciado algumas décadas antes da publicação do IRS, as razões para seu fechamento a essa obra talvez sejam ainda mais claras, remetendo a uma crítica a seus supostos conservadorismo e vínculo com o funcionalismo de Parsons (1951). É sabido que Dunlop concentra seus argumentos sobre o funcionamento dos sistemas de relações de trabalho nos marcos de uma economia industrial capitalista ${ }^{16}$. Isso, no entanto, está obviamente longe de nos fazer crer que o arcabouço conceitual e as descobertas analíticas decorrentes de suas pesquisas empíricas sejam conservadores ou desprezíveis. Dunlop, ao acolher a ideia de conflito como algo inerente ao funcionamento das sociedades industriais, posiciona-se fora do que se poderia chamar de strong functionalism, corrente hegemônica nas interpretações sociológicas da época. Essa corrente postulava que a coesão, ou ordem social, se dá como fruto de um consenso partilhado por todos, expurgando a ideia de conflito. Ao contrário do funcionalismo, a ideia de conflito - que coexiste com as ideias de cooperação e consenso - está presente no centro e opera como motivação do enfoque analítico e das perspectivas normativas de Dunlop para as relações de trabalho. Seu enfoque sistêmico sobre essas relações seguramente não é uma aplicação da teoria de Parsons sobre o funcionamento da sociedade ${ }^{17}$.

\section{LIÇÕES DO INDUSTRIAL RELATIONS SYSTEMS CINQUENTA ANOS DEPOIS}

Cinquenta anos após a edição pioneira do Industrial Relations Systems, mudanças na economia e na sociedade, ocorridas sobretudo a partir dos anos 1970, construíram um mundo do trabalho que em muitos aspectos difere daquele no qual Dunlop escreveu sua obra. Entre outras transformações representativas, as últimas décadas viram surgir um sem-número de inovações tecnológicas e organizacionais aplicadas à produção, novos arranjos produtivos foram introduzidos e novas institucionalidades nas relações entre capital, trabalho e governo, nos níveis micro, meso e macrorregulatórios, foram edificadas em todos os países industrializados. 
No entanto, é preciso ter presente que essas transformações não alteraram completamente todas as dimensões do trabalho. O novo coexiste com o velho; observam-se também continuidade, resiliência, inércia. A automação flexível, por exemplo, pode ter aplicação simultânea com os padrões organizacionais tipicamente tayloristas. Sindicatos de trabalhadores e patronais podem resistir em afastar-se da tutela estatal por força da cultura política presente em determinada formação social. Se o mundo do trabalho mudou, mas não é absolutamente novo, retomar o exame do IRS cinquenta anos depois nos posiciona diante de questões como se nele ainda existem elementos analíticos relevantes para entender o mundo do trabalho e que elementos são esses.

A obra de Dunlop merece ser destacada, primeiramente, em virtude da produção de uma reflexão sistemática e teórica sobre as relações de trabalho. Muito antes desse autor, ao longo de toda a modernidade ocidental, os estudos sobre o trabalho, seus atores e instituições estiveram presentes em vasta literatura. Contudo, no IRS, as relações de trabalho são enquadradas na condição de um objeto de estudo particular - o sistema de relações de trabalho -, com um corpo teórico próprio. Ainda que o resultado final permaneça aberto às mais variadas disputas, um mérito claro de Dunlop reside exatamente em sua insistência para com a necessidade de formulação teórica em um campo de estudos, o do industrial relations, até então caracterizado por um excesso de estudos descritivos. Como o autor aponta no prefácio, esse era um campo em que "os fatos vêm ultrapassando as ideias. Uma teoria integrativa tem ficado bem atrás da experiência em expansão" (Dunlop, 1993:x; tradução dos autores). Dunlop lançou-se, então, em busca de um arcabouço conceitual e teórico que permitisse interpretar esses fatos e práticas das relações de trabalho.

Em sua busca de uma teoria geral, Dunlop amplia o escopo analítico das relações de trabalho ${ }^{18}$. Estas são enquadradas como o resultado de uma diversificada teia de relações e interações, em um entendimento que supera abordagens que enfatizam dimensões particulares, como a técnica (Taylor) ou a psicossocial (Elton Mayo). No Industrial Relations Systems, as relações de trabalho inserem-se em um patamar de complexidade com múltiplos condicionantes e relações de interdependência. A empresa, conquanto seja o núcleo do sistema de produção e da relação de emprego, não é tomada como o locus exclusivo e insulado das relações de trabalho. As práticas das relações de trabalho, no arcabouço 
do IRS, sujeitam-se a imperativos de variada natureza, tais como técnicos, de mercado, ideológicos e de distribuição de poder.

Por meio da abordagem sistêmica, o IRS valoriza as relações de interdependência dos atores das relações de trabalho, quer estes sejam vistos individualmente - trabalhadores e empregadores -, quer sejam tomados de modo organizado - como na formulação dunlopiana das hierarquias - ou institucional. Sem enfrentar aqui as discussões mais gerais das ciências sociais em torno do enfoque sistêmico, cabe assinalar que essa perspectiva relacional torna evidente ainda tanto a existência de conexões e nexos entre diferentes dimensões das relações de trabalho quanto as estruturas sociais subjacentes na conformação das normas que regulam essas relações.

No âmbito da dimensão metodológica, a obra de Dunlop sugere uma valorização da investigação empírica. Nisso reside uma diferença fundamental entre ele e o sociólogo Talcott Parsons (1902-1979), cuja teoria dos sistemas teria influenciado a redação do IRS. Parsons preocupou-se menos com a problematização de dimensões empíricas da realidade, direcionando sua energia intelectual para a elaboração de uma intricada teoria, marcadamente abstrata e com pretensões totalizantes, sobre o funcionamento da sociedade. No IRS, porém, o sistema não possui uma existência acima dos atores concretos, dos mercados, da tecnologia, da ideologia e das relações de poder. Em suma, o sistema de relações de trabalho não existe fora da história e dos contextos em que os atores interagem. Dunlop mesmo desenvolveu um esforço de pesquisa empírica nas mais diferentes realidades do trabalho, inclusive fora dos Estados Unidos, buscando apreender o funcionamento de sistemas de relações de trabalho e a elaboração das normas. Anorma, bem como o que ela carrega em seu interior como força reguladora, é vista como expressão de relações sociais históricas que precisam ser apreendidas mediante sistemático trabalho de investigação empírica.

Ainda que não encontremos tal postulação de modo explícito no IRS, decorre, do modo como Dunlop define e elabora seu objeto de estudo, o enquadramento multidisciplinar do campo das relações de trabalho. Podemos dizer que Dunlop, ao examinar diversas realidades empíricas, mostra que a formação da norma e aquilo que ela procura estruturar nas relações entre os atores só são compreendidos mediante o entendimento de singularidades culturais, econômicas, religiosas e políticas 
próprias de cada formação social; e que o sucesso de tal empreendimento demanda o concurso de diversos campos de conhecimento.

Por fim, cabe ressaltar uma dimensão política central que decorre da obra de Dunlop, ou seja, seu reconhecimento de que as relações de trabatho abrigam interesses diferentes, o que é designado como perspectiva pluralista. Tal perspectiva não raramente se mescla com elementos analíti$\cos$ da obra do autor. Uma de suas consequências principais é a noção de que as relações de trabalho podem expressar o consenso, mas também o conflito, algo a que normalmente se refere como o motivo misto da cooperação e do conflito ${ }^{19}$. Há, portanto, na obra de Dunlop um esforço para posicionar o conflito como algo inerente às relações de trabalho, pois estas abrigam, em seu interior, interesses divergentes. Da mesma forma, o pluralismo dunlopiano implica que os atores sejam efetivamente protagonistas na resolução dos $\operatorname{conflitos}^{20}$.

(Recebido para publicação em janeiro de 2009)

(Versão definitiva em setembro de 2009) 


\section{Carlos Henrique Horn, Fernando Coutinho Cotanda e Walter Arno Pichler}

\section{NOTAS}

1. As menções à obra de Dunlop na literatura especializada brasileira (e sobre o Brasil) são, ou indiretas, ou esparsas. No primeiro grupo, há que se apontar os textos pioneiros de Mericle (1974) e Pastore e Zylberstajn (1988), por sua alusão ao termo “sistema de relações de trabalho", ainda que Dunlop não seja referido na bibliografia da obra dos brasileiros. Já no segundo grupo, um autor isolado em sua referência explícita a Dunlop é Carvalho Neto (Melo e Carvalho Neto, 1998; Carvalho Neto, 2001), e uma discussão bastante crítica do conceito dunlopiano de sistema de relações de trabalho encontra-se em Galvão (2002).

2. Há tradução do Industrial Relations Systems para o espanhol. Ver, por exemplo, Dunlop (1978).

3. Hoje, Labor and Employment Relations Association (Lera).

4. A obra é arrolada na lista de publicações do Estudo Interuniversitário dos Problemas do Trabalho no Desenvolvimento Econômico, elaborada por Kerr et alii (1963).

5. A industrialização é "a grande transformação na longa história da humanidade neste planeta - mais básica, mais rápida e mais universal do que qualquer outra transformação que jamais tenha ocorrido" (Kerr et alii, 1963:279). Há duas hipóteses - talvez fosse melhor chamá-las de pressupostos - que alimentam o Estudo Universitário em seu nascedouro no pós-guerra: (i) os países, ou inúmeros países, inevitavelmente experimentarão um período de industrialização; (ii) como consequência, esses países vivenciarão os problemas típicos da industrialização, sobretudo aqueles que se manifestam no âmbito da produção e das relações de trabalho.

6. Em 1975, os autores publicaram, no ensaio Industrialism and Industrial Man Reconsidered: Some Perspectives on a Study over Two Decades of the Problems of Labor and Management in Economic Growth, uma atualização de sua discussão central, mantendo algumas e modificando outras das principais conclusões apresentadas no Industrialism and Industrial Man, de 1960. O ensaio é considerado o último documento do Estudo, então renomeado Estudo Interuniversitário dos Recursos Humanos no Desenvolvimento Nacional. Ver Dunlop et alii (1975).

7. No comentário que escreveu à edição de 1993, Dunlop sustenta que o objeto de uma teoria das relações de trabalho deve ser a determinação de normas, mas também menciona as práticas das relações de trabalho: “[...] o foco analítico deste campo [relações de trabalho] é o que desenvolvemos no Industrial Relations Systems: as regras e as práticas do local de trabalho desenvolvem-se por meio da interação de gerentes, trabalhadores e suas organizações, e agências governamentais em um contexto de tecnologia, mercados de trabalho e produto, e regulamentações governamentais" (Dunlop, 1993:8; tradução dos autores).

8. A tradução literal de industrial relations para o português, ou seja, relações industriais, leva à perda de seu significado mais preciso, que se refere ao estudo das relações de trabalho. Assim, em prol da clareza e da precisão, convém abandonar a literalidade e seguir, por analogia, a orientação da Organização Internacional do Trabalho (OIT), que indica utilizar a expressão relaciones laborales para a tradução do termo para o espanhol, passando, portanto, a usar a expressão relações de trabalho como a melhor tradução de industrial relations para o português. 
9. Nossa referência é a edição de 1993 da Harvard Business School, na qual também aparece um comentário novo do autor, redigido especialmente para essa edição.

10. Wood et alii (1975), em seu excelente ensaio interpretativo sobre o conceito de sistema de relações de trabalho na obra de Dunlop, assinalam que "a 'teia de normas' é vista como o produto do sistema de relações de trabalho, o qual, por sua vez, é compreendido como um sistema de formulação de regras" (ibidem:295; tradução e ênfases dos autores). Elaboram ainda, em conformidade com o marco dunlopiano, uma distinção analítica entre o sistema que produz as normas (isto é, o sistema de relações de trabalho) e o sistema que é regulado por tais normas (isto é, o sistema produtivo).

11. Goodman et alii (1975), em sua detalhada elaboração sobre o conceito de normas na teoria das relações de trabalho com base em Dunlop, e Flanders (1970:24) assinalam a natureza distinta dos dois tipos de normas ao sintetizar que "normas substantivas definem os postos de trabalho, enquanto normas de procedimento regulam o processo de elaboração normativa".

12. De acordo com Edwards (1995:13), o estabelecimento de normas no lugar de trabalho e na comunidade de trabalho constitui um processo social complexo, que depende do poder, do conhecimento e da organização dos atores.

13. Podemos arguir, em conformidade com o IRS, que, nesse caso, a legislação preexistente deveria ser considerada um dos elementos de contexto de um sistema, no qual os atores decidem sobre normas que se exprimem, entre outras formas, por meio de nova legislação.

14. Esta seção foi sugerida por um parecerista, a quem devemos especial agradecimento, pois nos permitiu uma rica discussão cujos apontamentos, ainda que meramente exploratórios neste artigo, sugerem uma linha de abordagem a que pretendemos retornar em breve.

15. Mais recentemente, a partir de Noronha $(1999 ; 2000)$, pesquisadores passaram a designar o modelo brasileiro como "legislado", enfatizando a forte primazia estatal na criação da norma. Já Pichler (2002; 2005) utiliza a expressão "modelo estatutário de barganha" (ou "modelo legislado de barganha") para destacar que, a par da primazia estatal, a evolução do sistema brasileiro a partir de fins da década de 1970 teria abrigado também um papel não desprezível para a negociação coletiva.

16. Cabe lembrar, todavia, que o enfoque sistêmico se propunha a explicar a criação de normas aplicáveis às relações de trabalho independentemente do modo predominante de produção. Dunlop e seus parceiros do Estudo Interuniversitário examinaram diferentes tipos de economia, neles incluídos os de planejamento central.

17. A propósito das diferenças entre Parsons e o enfoque sistêmico de Dunlop, ver Wood et alii (1975).

18. Uma visão diferente é a de Kaufman (1993) que, em passagem na qual comenta o IRS e sua importância para o campo de estudos do industrial relations nos Estados Unidos, julga que a obra de Dunlop teria sido responsável pelo estreitamento desse campo: "[...] Dunlop apresentou o campo de estudos com uma escolha clara. Se fosse seguido o modelo por ele exposto, o campo efetivamente perderia a escola de gestão de pessoas e suas disciplinas científicas comportamentais e se constituiria de um modo mais estreito e rigoroso, orientado para a disciplina da economia (e, em menor grau, do direito), para o estudo dos sindicatos e da negociação coletiva, e para a perspecti- 


\section{Carlos Henrique Horn, Fernando Coutinho Cotanda e Walter Arno Pichler}

va política da escola dos economistas institucionalistas" (ibidem:102; tradução dos autores).

19. Dunlop, portanto, distancia-se dos marxistas, que consideram irreconciliável a relação entre capital e trabalho; das correntes que não aceitam os sindicatos independentes como interlocutores legítimos dos trabalhadores e veem em sua ação um entrave ao sucesso econômico das empresas; e das correntes interpretativas das relações de trabalho que postulam ser a empresa uma comunidade de interesses comuns, cujos atores teriam objetivos idênticos (unitarismo).

20. Em países de tradição voluntarista, a afirmação sobre o protagonismo dos atores é normalmente tomada com maior grau de aceitação do que em países onde a diferença dos interesses de empregadores e de empregados é massivamente negada, e que o conflito entre capital e trabalho é entendido como um mal a ser remediado por meio da ação do Estado que tutele os atores.

\section{REFERÊNCIAS BIBLIOGRÁFICAS}

CARVALHO NETO, Antônio Moreira de. (2001), Relações de Trabalho e Negociação Coletiva na Virada do Milênio: Estudo em Quatro Setores Dinâmicos da Economia Brasileira. Belo Horizonte/Rio de Janeiro, IRT-PUC-MG/Vozes.

DUNLOP, John T. (1978), Sistemas de Relaciones Industriales. Barcelona, Ediciones Peninsula.

. (1993) [1958], Industrial Relations Systems (ed. revista). Boston, HBS Press.

et alii. (1975), Industrialism and Industrial Man Reconsidered: Some Perspectives on a Study over Two Decades of the Problems of Labor and Management in Economic Growth. Princeton, Princeton University Press.

EDWARDS, Paul. (1995), “The Employment Relationship", in P. Edwards (ed.), Industrial Relations: Theory and Practice in Britain. Oxford, Blackwell, pp. 3-26.

FLANDERS, Allan. (1970) [1968], Management and Unions: The Theory and Reform of Industrial Relations. London, Faber and Faber.

GALVÃO, Andréia. (2002), O Sistema de Relações de Trabalho em Xeque: Uma Nota Conceitual. Anais do XXVI Encontro Anual da Associação Nacional de Pós-Graduação e Pesquisa em Ciências Sociais (Anpocs), Caxambu, MG.

GOODMAN, John F. B. et alii. (1975), "Rules in Industrial Relations Theory: A Discussion". Industrial Relations Journal, vol. 6, o 1, pp. 14-30.

HUMPHREY, John. (1982), Fazendo o Milagre: Controle Capitalista e Luta Operária na Indústria Automobilística Brasileira. Petrópolis, Vozes.

KAUFMAN, Bruce E. (1993), The Origins and Evolution of the Field of Industrial Relations in the United States. Ithaca, ILR Press/Cornell University Press. 
. (2004), The Global Evolution of Industrial Relations: Events, Ideas and the IRRA. Genebra, International Labour Office.

KERR, Clark et alii. (1963) [1960], El Industrialismo y el Hombre Industrial: Los Problemas del Trabajo y la Dirección en el Desarrollo Económico. Buenos Aires, EUDEBA-INSORA.

MELO, Marlene Catarina de O. Lopes e CARVALHO NETO, Antônio Moreira de. (1998), Negociação Coletiva e Relações de Trabalho: O Debate Atual. São Paulo, ABET.

MERICLE, Kenneth Scott. (1974), Conflict Regulation in the Brazilian Industrial Relations System. Dissertação de Ph.D. em Relações Industriais, Universidade Madison, de Wisconsin.

MÜLLER-JENTSCH, Walther. (2004), "Theoretical Approaches to Industrial Relations", in B. E. Kaufman (ed.), Theoretical Perspectives on Work and the Employment Relationship. Champaign, IL, IRRA-Industrial Relations Research Association Series, cap. 1.

NORONHA, Eduardo G. (1999), Entre a Lei e a Arbitrariedade: Mercados e Relações de Trabatho no Brasil. São Paulo, Ltr.

. (2000), “O Modelo Legislado de Relações de Trabalho no Brasil”. DADOS, vol. 43, no 2, pp. 241-290.

PARSONS, Talcott. (1951), The Social System. New York, Free Press.

PASTORE, José e ZYLBERSTAJN, Hélio. (1988) [1985], A Administração do Conflito Trabalhista no Brasil ( $2^{\mathrm{a}}$ ed.). São Paulo, IPE-USP.

PICHLER, Walter A. (2002), “Mudanças no Sistema Brasileiro de Relações de Trabalho entre 1978 e 1991". Ensaios FEE, vol. 23, № 2, pp. 867-898.

. (2005), Changing Industrial Relations in Brazil: Developments in Collective Bargaining in Rio Grande do Sul, 1978-1991. Dissertação de Ph.D. em Relações Industriais, London School of Economics and Political Science, London.

SALAMON, Michael. (1998), Industrial Relations: Theory and Practice. London, Prentice Hall.

WOOD, Stephen J. et alii (1975), “The 'Industrial Relations System' Concept as a Basis for Theory in Industrial Relations". British Journal of Industrial Relations, vol. 13, no 3, pp. 291-308. 


\section{ABSTRACT \\ John T. Dunlop and the $50^{\text {th }}$ Anniversary of Industrial Relations Systems}

This paper addresses John Thomas Dunlop's Industrial Relations Systems, a book that has exerted enormous influence on research concerning employment relations in the Anglo-American industrial relations tradition in the last 50 years. Following a note on the author and commentary on the academic context in which the book emerged, the paper revisits "employment relations system" as a key concept and presents the elements of such a system according to Dunlop's analytical framework. Two brief sections complete the paper, one inquiring into the lack of references to Dunlop by Brazilian researchers and the other drawing some essential lessons from the book.

Key words: employment relations; John T. Dunlop; employment relations system

\section{RÉSUMÉ}

John T. Dunlop et les 50 ans de 1'Industrial Relations Systems

Dans cet article, on présente l'oeuvre Industrial Relations Systems, de John Thomas Dunlop, publiée en 1958, qui a exercé une grande influence dans l'étude des relations du travail dans l'industrie selon la tradition anglo-américaine des Industrial relations au long des 50 dernières années. Outre une note biographique sur l'auteur et la présentation du cadre universitaire à l'origine de l'ouvrage, dans cet article on réexamine le concept-clé de système des relations du travail dans l'industrie tout en présentant les éléments qui composent ce système en accord avec le caractère analytique de Dunlop. Deux brèves sections complètent l'article: l'une sur les raisons de l'absence de Dunlop au Brésil, et l'autre tirant quelques leçons du livre.

Mots-clé: relations du travail; John T. Dunlop; système des relations du travail 